\title{
IN SEARCH OF THE MISSING LINK: SERUM LIPID PROFILE, TROPONIN T AND ACUTE CORONARY SYNDROME.
}

\author{
Basabdatta Samanta Mukhopadhyay¹, Bharti Kawatra Uppal2, Sandip Mukhopadhyay³
}

\section{HOW TO CITE THIS ARTICLE:}

Basabdatta Samanta Mukhopadhyay, Bharti Kawatra Uppal, Sandip Mukhopadhyay. "In search of the Missing Link: Serum Lipid Profile, Troponin T and Acute Coronary Syndrome". Journal of Evolution of Medical and Dental Sciences 2014; Vol. 3, Issue 02, January 13; Page: 726-732, D0I:10.14260/jemds/2014/1893

ABSTRACT: Acute coronary syndrome is one of the leading causes of morbidity and mortality worldwide, hyperlipidemias being a major predisposing factor. Cardiac Troponin T (cTnT) is one of the most sensitive and specific biomarkers of myocardial injury.

The aim of the study was to evaluate the relationship among TnT levels and lipid profiles of different age groups of patients with ACS, and to determine if any the association of age with lipid profile and TnT levels. The lipid profiles and TnT levels were determined in 464 patients with acute

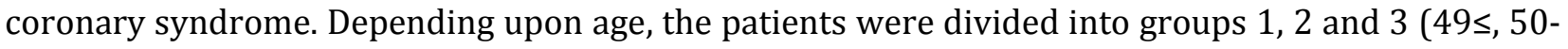
69 and $\leq 70$ years respectively). Increasing age was found to be associated with fall in mean levels of total cholesterol, LDL, triglycerides and TnT.

Our study suggested that among patients with ACS, there exists a relation between age, lipid components and TnT levels. TnT is known to be an independent predictor of the outcome of myocardial ischemia. Further studies are therefore required to ascertain the validity of TnT as a prognostic cardiac biomarker among the elderly.

INTRODUCTION: Acute coronary syndrome (ACS) refers to a constellation of clinical symptoms caused by acute myocardial ischemia. ${ }^{1}$ ACS has a complex etiology. Among the various causes, the most common is coronary artery atherosclerosis with erosion or rupture of the fibrous cap of the atherosclerotic plaque, leading to exposure of prothrombotic core components to the circulation and intracoronary thrombus formation.1, 2 The well-defined risk factors for atherosclerosis include advancing age, male sex, smoking, diabetes, hypertension, hyperlipidemia, psychosocial stress and a sedentary life style. ${ }^{3,4}$

Hyperlipidemias are long known to be associated with atherosclerosis; an increase in total cholesterol and LDL accompanied by a decrease in HDL being the major risk factors. ${ }^{3}$ Chronic hyperlipidemia, in particular hypercholesterolemia causes endothelial cell dysfunction by increasing production of free radicals which injure tissues and accelerate nitric oxide decay, impairing its vasodilator function. ${ }^{5}$ Chronic hyperlipidemia causes intimal accumulation and free radical oxidation of lipoproteins. Oxidized low density lipoprotein (LDL) exerts several biological effects that may contribute to the progression of the atherosclerotic lesion. Foam cells, the hallmark cells of atherosclerosis, are formed by scavenger receptor mediated uptake and accumulation of oxidized LDL. ${ }^{6}$ Oxidized LDL attracts monocytes and T lymphocytes and inhibits macrophage motility, promoting their retention in the arterial wall. In addition, oxidized LDL stimulates expression of certain arterial wall genes e.g. interleukin 1 (IL-1), which induce smooth muscle cell proliferation, leukocyte-endothelial cell adhesion and promote a procoagulant state. ${ }^{7}$ Metalloproteinases released from foam cells and macrophages cause extracellular matrix degradation, plaque instability and fibrous cap rupture, precipitating thrombus formation, myocardial ischemia and if prolonged, 
myocardial cell necrosis. ${ }^{8}$ High density lipoprotein (HDL) on the other hand is well known for its anti atherogenic properties; inhibition of LDL oxidation and promotion of reverse cholesterol transport being the major contributory factors. ${ }^{9}$ The association of coronary artery disease (CAD) with total cholesterol however declines somewhat with age, particularly in females. Meta-analysis has shown significant prediction of CAD by raised LDL levels in elderly males, and low HDL levels in elderly females. ${ }^{3}$

The National Academy of Clinical Biochemistry, USA recommends the use of various biochemical markers in the initial evaluation, diagnosis and management of patients with ACS. Among the available biomarkers, cardiac Troponins (I and T) are the most sensitive and tissue specific for the diagnosis of myocardial necrosis. ${ }^{1}$

Troponin, a protein component of the contractile apparatus of striated muscle is expressed in three different isoforms, one for slow-twitch skeletal muscle fibers, one for fast-twitch skeletal muscle fibers, and one for cardiac muscle (cTnI, cTnT). ${ }^{10}$ Though they differ in intracellular compartments, biological half-life and molecular weight, cTnT and cTnI are almost equally sensitive in the diagnosis of myocardial necrosis. ${ }^{11}$ Elevated TnT is detectable in the serum of patients with acute myocardial infarction within 3-4 hours of the attack, and remains elevated for up to 14 days. Unlike CK MB, TnT is also elevated in patients with unstable angina at increased risk for future cardiac events. Besides, TnT has been proven to be an independent predictor of outcome of myocardial ischemia, and a useful tool in guiding anti- thrombotic therapy. ${ }^{1}$ Hence cardiac troponins are now said to be the "gold" standard biochemical marker for diagnosis and management of patients with ACS. ${ }^{12}$ Knowing the relationship of dyslipidemias and ACS, in this study we aimed to evaluate the relationship among TnT levels and lipid profiles of different age groups of patients with ACS, and to determine if any the association of age with the lipid profile and TnT levels.

MATERIALS AND METHODS: The study was a one year retrospective study enrolling 464 patients admitted with ACS in Christian Medical College, Ludhiana. All had been admitted to the coronary care unit with complaints of chest pain and diagnosed to have ACS on the basis of history, clinical features, changes in the electrocardiogram and a diagnostic rise of cardiac enzymes. 309(66.5\%) of the patients were males, 155(33.4\%) were females, with mean age of 60.8 years. Depending upon age, the patients were divided into groups 1, 2 and 3 (age 49 5, 50-69 and $\geq 70$ years respectively). Blood samples for TnT were taken on admission, and thereafter every $12 \mathrm{hrs}$, as per the hospital protocol; the highest TnT attained by each patient was taken into consideration. Fasting (overnight from $10 \mathrm{pm}$ ) samples were taken as early as possible for lipid profile. TnT levels were measured using the TnT STAT Elecsys system, ECLIA, on Elecsys 2010. Lipid profile was done on Hitachi P800 modular auto-analyzer.

Statistical Analysis: Statistical analysis was done using SPSS software, version 16. Mean and standard deviation of total cholesterol (TC), LDL, HDL, triglycerides (TG) and TnT was calculated in the different groups. One way ANOVA was used to compare the means among different groups, Bonferroni correction was done post HOC. A p value $<0.05$ was considered statistically significant.

RESULTS: The differences of values of the different lipid components with respect to age are shown in table 1. Excepting HDL levels, all other components of the lipid components were found to be 
reduced with increasing age. These reductions are statistically significant. (Table 1)

The fall in total cholesterol and LDL levels was highly significant, with $\mathrm{p}<0.001$ between group 1 and 3, and p < 0.001 between group 2 and 3 for both LDL and cholesterol. The TG levels in group 3 similarly were significantly lower than group $1(p=0.002)$ and group $2(p=0.016)$. TnT levels followed a similar trend, the difference however being statistically significant only between group 1 and $3(\mathrm{p}=0.03)$. Between groups 1 and 2 , there was a clinically but not statistically significant fall in mean levels of each of the above parameters. However, there was no significant difference in mean HDL levels among any of the groups. (Table 1)

In the sub-group of males, a similar trend was followed, i.e. decreasing mean lipid and TnT levels with increasing age. However, only the cholesterol and LDL values could reach the level of statistical significance. (Figure 1) The fall in TG levels in this case however was clinically but not statistically significant $(\mathrm{p}=0.069)$. (Table 2$)$

The trend in case of females was slightly different. With increasing age there was a clinical but not statistically significant fall in total cholesterol and LDL levels, accompanied by a rise in mean HDL levels. TG levels fell significantly between group 1 and $3(p=0.05)$. There was a fall in mean TnT levels from group 1 to group 2, followed by a rise in group 3, the difference however not being significant statistically in any case. (Table 3) Changes in TnT level was also found to vary amongst the age group. However, the fall in the level with age was significant in males only. (Figure 2)

DISCUSSION: The present study demonstrated significant age associated variations of lipid and TnT levels among patients admitted with acute coronary syndrome. With increasing age, there was a gradual and significant fall in the levels of total cholesterol, LDL and TGs. This was accompanied by a fall in mean levels of TnT. The trend followed was similar in case of both males and females, extent of fall however being more significant in case of males. In elderly females $(\geq 70)$ there was a slight rise in mean TnT levels, as compared to the age group of $50-69$ years.

It is a known fact that the incidence of ACS is much higher among the elderly population. In the United States, patients more than 65 years of age alone account for half of the hospital admissions and $80 \%$ of the deaths due to myocardial infarction. ${ }^{13}$ Various risk factors are known to predispose towards the development of ischemic heart disease, including age, hyperlipidemias, diabetes, hypertension and a sedentary lifestyle. The relative risk attributable to these factors however varies somewhat among the elderly. ${ }^{3}$ Previous studies have shown that the prediction of ischemic heart disease by total cholesterol declines somewhat with increasing age, particularly in individuals $>70$ years of age. ${ }^{3}$ We too observed a fall in the lipid levels among elderly patients.

In the present study including all ACS patients admitted over a period of one year, $23.9 \%$ belonged to the age group of $\geq 70$ years. The mean cholesterol, LDL and TG levels of these patients were significantly lower than patients of both $\leq 49$ years, and $50-69$ years of age; whereas there was no significant difference in levels of the cardio protective HDL component. Lower lipid levels in this age group could be explained by lifestyle and dietary modifications, or due to the use of statins, the history of which was not available in this case. Similar findings were reported by Malaguarnera et al. They studied the lipid profiles of healthy individuals $>70$ years of age and found that the levels were lowest among those $>100$ years. ${ }^{14}$ It thus appears that in case of elderly individuals, it is not the lipid components but other factors which may contribute more towards the predisposition to heart disease. The small dense LDL levels however were not measured in this study. Small dense 
LDL comprises the atherogenic sub-type of LDL. It may be that among the elderly population, though there was a fall in the total LDL levels, there might have been a redistribution of LDL sub-fractions to a more atherogenic small, dense, sub-type.

Another interesting finding in this study was that along with lipid components, there was a fall in mean TnT levels with increasing age. cTnT being a protein component of the contractile apparatus of cardiac muscle is released only during myocardial necrosis. It is a very sensitive and specific marker of myocardial injury, released from myocardial cells in response to any ischemic attack ${ }^{15}$. In patients $>70$ years of age, we found that along with lipids, the mean TnT levels were also significantly lower than the younger age groups. Serum cholesterol is one of the major factors predisposing to atherosclerotic plaque formation and progression, and hence myocardial ischemia. Hence it appears that patients with lower lipid levels have lesser extent of myocardial damage in case of any ischemic attack. Previous studies however have reported that elderly patients with myocardial infarction present less frequently with ST segment elevation and have lesser extent of cardiac enzyme elevation. In case of females we found that the mean TnT levels in patients $>70$ years was slightly higher than that of the age group 50 - 69 years. This may be explained by the fact that the latter group contained peri menopausal and early post-menopausal women. The cardio protective effect of estrogen would be higher in this group than the group of $>70$ years of age with much lower estrogen levels. 16

A drawback of this study was that outcome of the patients was not taken into consideration. TnT is known to have both diagnostic and prognostic significance in ACS. In our study both lipid and TnT levels were lowest in patients $>70$ years of age, which implies lesser myocardial damage than younger patients and suggests a better prognosis. However it has been found in previous studies that due to associated co morbid conditions elderly people tend to have higher incidence of cardiovascular complications and poorer outcome than younger patients in case of any ischemic attack. ${ }^{13}$ This suggests that though TnT is useful as a diagnostic cardiac biomarker, its usefulness as a prognostic indicator in case of elderly patients with ACS is questionable.

CONCLUSIONS: In patients with acute coronary syndrome, advancing age is associated with fall in the mean levels of total cholesterol, LDL and triglycerides, accompanied by a fall in the mean levels of TnT. Hence TnT, though a good diagnostic biomarker, uncertainty exists regarding its prognostic significance among the elderly patients with acute coronary syndrome.

Conflict of interest: The authors declare no conflict of interest.

\section{REFERENCES:}

1. Morrow DA, Cannon CP, Jesse RL, et al. National Academy of Clinical Biochemistry Laboratory Medicine Practice Guidelines: clinical characteristic and utilization of biochemical markers in acute coronary syndromes. Clin Chem. 2007; 53: 552-74.

2. Libby P. Current concepts of the pathogenesis of the acute coronary syndromes. Circulation. 2001; 104: 365-72.

3. Simons LA, Friedlander Y, McCallum J, Simons J. Risk factors for coronary heart disease in the prospective Dubbo Study of Australian elderly. Atherosclerosis. 1995; 117:107-18.

4. Slopen N, Glynn RJ, Buring JE, Lewis TT, Williams DR, Albert MA. Job Strain, Job Insecurity, and 
Incident Cardiovascular Disease in the Women's Health Study: Results from a 10-Year Prospective Study. PLoS ONE. 2012; 7(7): e40512.

5. Kumar V, Abbas AK, Fausto N, Aster J. Robbins \& Cotran Pathologic Basis of Disease, 8th ed. Elsevier; 2007. Chapter No. 11; Blood Vessels; p. 1115.

6. Boullier A, Bird DA, Chang MK, Dennis EA, Friedman P, Gillotre-Taylor K et al. Scavenger receptors, oxidized LDL, and atherosclerosis. Ann NY Acad Sci.2001; 947:214-22.

7. Jialal I. Evolving lipoprotein risk factors: lipoprotein (a) and oxidized LDL. Clin Chem.1998; 44:1827-32.

8. Reddy RK, Reddy S, Kumar AN. Lipid Profile levels on the second day of Acute Myocardial Infarction; is it the right time for estimation? Internet Journal of Medical Update 2012 January; $7(1): 52-5$.

9. Feingold KR, Grunfeld C. The acute phase response inhibits reverse cholesterol transport. J Lipid Res 2010; 51:682-84.

10. Mair J. Cardiac troponin I and troponin T Are enzymes still relevant as cardiac markers? Clin Chim Acta. 1997;257:99-155

11. M. Adamcov'a. Troponins in children and neonates. Acta Paediatr. 2003; 92:1373-75.

12. Bonaca MP, Morrow DA. Defining a role for novel biomarkers in acute coronary syndromes. Clin Chem 2008; 54:1424-31.

13. Mehta RH, Rathore SS, Radford MJ, Wang Y, Krumholz HM. Acute myocardial infarction in the elderly. differences by age. J Am Coll Cardiol. 2001; 38:736-41.

14. Malaguarnera M, Giugno I, Ruello P, Rizzo M, Panebianco MP, Pistone G et al. Lipid profile variations in a group of healthy elderly and centenarians. Eur Rev Med Pharmacol Sci. 1998; 2:75-9.

15. Bonaca MP, Morrow DA. Defining a role for novel biomarkers in acute coronary syndromes. Clin Chem 2008; 54:1424-31.

16. Godsland IF, Wynn V, Crook D, Miller NE. Sex, plasma lipoproteins, and atherosclerosis: prevailing assumptions and outstanding questions. Am Heart J. 1987; 114:1467-1503.

\begin{tabular}{|l|c|c|c|c|}
\hline & $\begin{array}{c}\text { Group 1 } \\
\text { Age } \leq 49 \text { yrs. } \\
(\mathrm{n}=67)\end{array}$ & $\begin{array}{c}\text { Group 2 } \\
\text { Age }=50-69 \text { yrs. } \\
(\mathrm{n}=284)\end{array}$ & $\begin{array}{c}\text { Group 3 } \\
\text { Age } \geq 70 \text { yrs. } \\
(\mathrm{n}=113)\end{array}$ & p value \\
\hline Total Cholesterol $(\mathrm{mg} / \mathrm{dl})$ & $175.66 \pm 47.88$ & $167.83 \pm 48.51$ & $145.09 \pm 47.54$ & $<0.001^{* *}$ \\
\hline HDL $(\mathrm{mg} / \mathrm{dl})$ & $35.39 \pm 10.68$ & $38.71 \pm 12.63$ & $38.56 \pm 13.75$ & 0.133 \\
\hline LDL $(\mathrm{mg} / \mathrm{dl})$ & $113.45 \pm 41.92$ & $104.97 \pm 41.34$ & $86.95 \pm 37.86$ & $<0.001^{* *}$ \\
\hline TG $(\mathrm{mg} / \mathrm{dl})$ & $138.10 \pm 66.16$ & $124.73 \pm 67.55$ & $104.90 \pm 48.84$ & $0.002^{* *}$ \\
\hline TnT $(\mathrm{ng} / \mathrm{ml})$ & $5.72 \pm 5.43$ & $4.27 \pm 6.46$ & $3.37 \pm 5.24$ & $0.039^{*}$ \\
\hline
\end{tabular}

Table 1: Lipid components \& TnT levels in different age groups of patients

Values are represented as mean \pm SD. $(*)$ implies that the $p<0.05$. $\left(^{* *}\right)$ implies that $p$ value $<0.01$ 


\begin{tabular}{|l|c|c|c|c|}
\hline & $\begin{array}{c}\text { Group 1 } \\
\text { Age } \leq 49 \text { yrs. } \\
(\mathrm{n}=49)\end{array}$ & $\begin{array}{c}\text { Group 2 } \\
\text { Age }=50-69 \text { yrs. } \\
(\mathrm{n}=195)\end{array}$ & $\begin{array}{c}\text { Group 3 } \\
\text { Age } \geq 70 \text { yrs. } \\
(\mathrm{n}=65)\end{array}$ & p value \\
\hline Total Cholesterol $(\mathrm{mg} / \mathrm{dl})$ & $171.02 \pm 45.15$ & $165.87 \pm 47.71$ & $133.83 \pm 40.14$ & $<0.001^{* *}$ \\
\hline HDL $(\mathrm{mg} / \mathrm{dl})$ & $35.50 \pm 9.68$ & $37.23 \pm 11.59$ & $34.91 \pm 14.19$ & 0.334 \\
\hline LDL $(\mathrm{mg} / \mathrm{dl})$ & $107.98 \pm 41.41$ & $104.09 \pm 41.03$ & $79.28 \pm 31.47$ & $<0.001^{* *}$ \\
\hline TG $(\mathrm{mg} / \mathrm{dl})$ & $137.81 \pm 64.38$ & $126.73 \pm 74.25$ & $108.53 \pm 54.42$ & 0.069 \\
\hline TnT $(\mathrm{ng} / \mathrm{ml})$ & $5.58 \pm 5.68$ & $4.74 \pm 6.86$ & $2.71 \pm 4.42$ & $0.03^{*}$ \\
\hline
\end{tabular}

Table 2: Lipid components \& TnT in different age groups of males

Values are represented as mean \pm SD. $(*)$ implies that the $p<0.05$. $\left(^{* *}\right)$ implies that $p$ value $<0.01$

\begin{tabular}{|c|c|c|c|c|}
\hline & $\begin{array}{c}\text { Group 1 } \\
\text { Age } \leq 49 \text { yrs. } \\
(\mathrm{n}=18)\end{array}$ & $\begin{array}{c}\text { Group 2 } \\
\text { Age }=50-69 \text { yrs. } \\
(\mathrm{n}=89)\end{array}$ & $\begin{array}{c}\text { Group 3 } \\
\text { Age } \geq 70 \text { yrs. } \\
(\mathrm{n}=48)\end{array}$ & p value \\
\hline Total Cholesterol (mg/dl) & $180.94 \pm 56.21$ & $172.20 \pm 50.26$ & $160.43 \pm 52.70$ & 0.287 \\
\hline HDL (mg/dl) & $34.65 \pm 14.33$ & $41.99 \pm 14.19$ & $43.53 \pm 11.53$ & 0.064 \\
\hline LDL (mg/dl) & $123.53 \pm 45.10$ & $106.91 \pm 42.19$ & $97.40 \pm 43.35$ & 0.096 \\
\hline TG (mg/dl) & $130.29 \pm 54.74$ & $120.32 \pm 49.79$ & $99.96 \pm 40.05$ & $0.025^{*}$ \\
\hline TnT (ng/ml) & $6.24 \pm 5.45$ & $3.23 \pm 5.48$ & $4.27 \pm 6.12$ & 0.120 \\
\hline
\end{tabular}

Table 3: Lipid components $\&$ TnT in different age groups of females

Values are represented as mean \pm SD. $(*)$ implies that the $p<0.05$. (**) implies that $p$ value $<0.01$

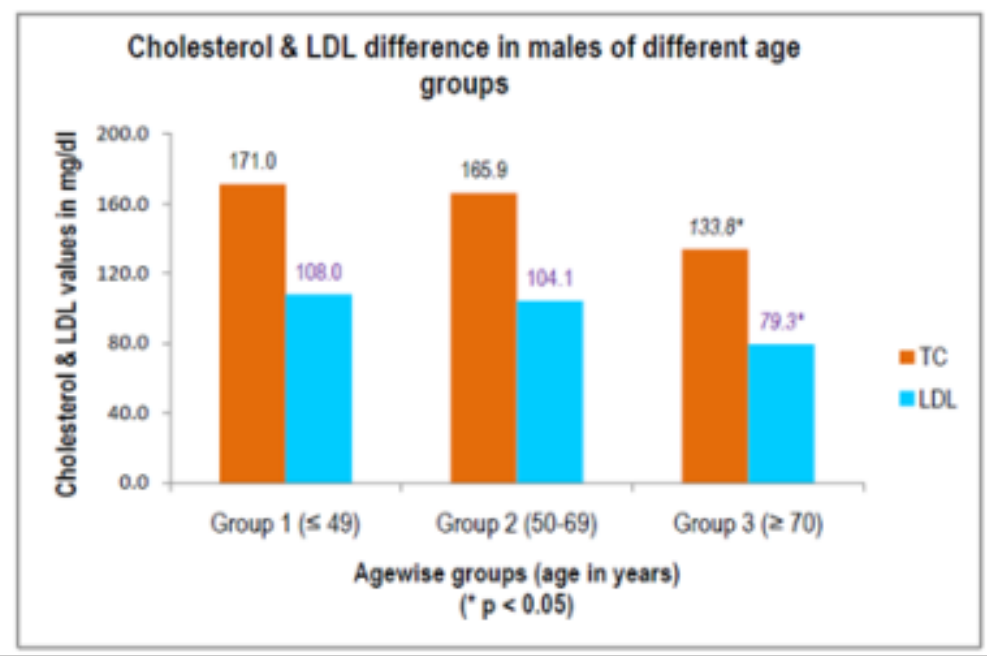

Fig. 1: Cholesterol and LDL difference in males of different age groups 


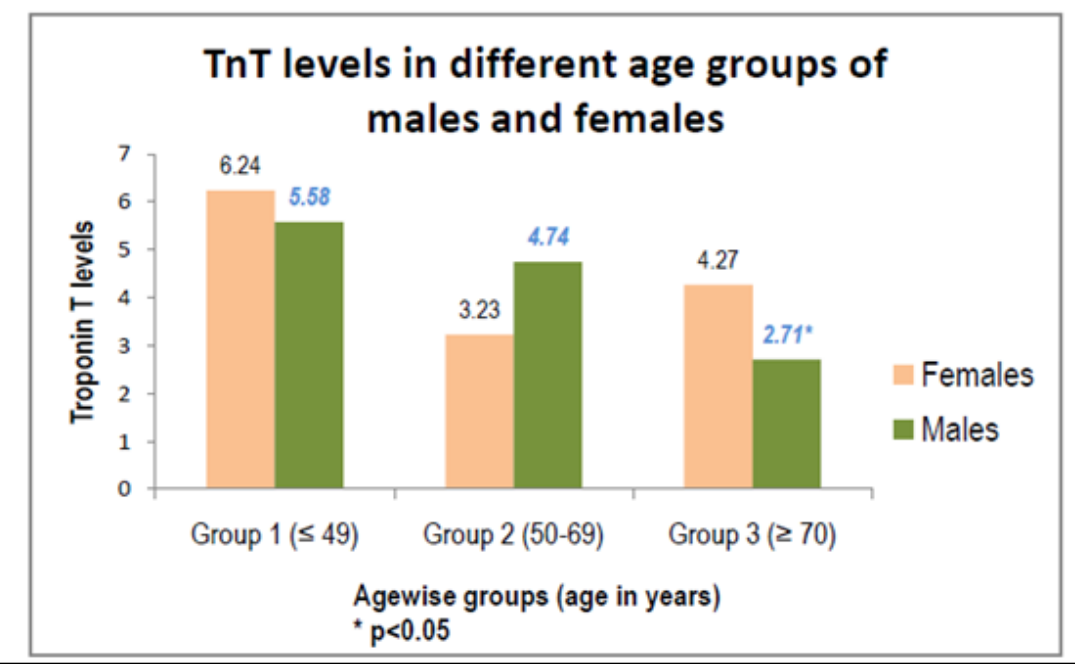

Fig. 2: TnT Levels in different age groups of males and females

\section{AUTHORS:}

1. Basabdatta Samanta Mukhopadhyay

2. Bharti Kawatra Uppal

3. Sandip Mukhopadhyay

\section{PARTICULARS OF CONTRIBUTORS:}

1. Assistant Professor, Department of Biochemistry, IQ City Medical College, Durgapur.

2. Professor \& Head of Department, Department of Biochemistry, Christian Medical College, Ludhiana.

3. Demonstrator, Department of Pharmacology, Christian Medical College, Ludhiana.

\section{NAME ADDRESS EMAIL ID OF THE} CORRESPONDING AUTHOR:

Dr. Basabdatta Samanta Mukhopadhyay, c/o. Dr. A.N. Samanta Alamganj, Burdwan, West Bengal, Pin - 713102 .

Email - basab_s@yahoo.com

Date of Submission: 25/12/2013.

Date of Peer Review: 26/12/2013.

Date of Acceptance: 08/01/2014.

Date of Publishing: 17/01/2014. 